\title{
Cost-Effectiveness Analysis of Prophylaxis Treatment Strategies to Reduce the Incidence of Febrile Neutropenia in Patients with Early-Stage Breast Cancer or Non-Hodgkin Lymphoma
}

\author{
Kelly Fust ${ }^{1} \cdot$ Xiaoyan $\mathrm{Li}^{2} \cdot$ Michael Maschio ${ }^{3}$ Guillermo Villa ${ }^{4} \cdot$ Anju Parthan ${ }^{1}$. \\ Richard Barron $^{2} \cdot$ Milton C. Weinstein $^{5} \cdot$ Luc Somers $^{6} \cdot$ Caroline Hoefkens $^{7}$ • \\ Gary H. Lyman ${ }^{8}$
}

Published online: 7 December 2016

(c) The Author(s) 2016. This article is published with open access at Springerlink.com

\begin{abstract}
Objective The objective of this study was to evaluate the cost effectiveness of no prophylaxis, primary prophylaxis (PP), or secondary prophylaxis (SP) with granulocyte colony-stimulating factors (G-CSFs), i.e., pegfilgrastim, lipegfilgrastim, filgrastim (6- and 11-day), or lenograstim (6- and 11-day), to reduce the incidence of febrile neutropenia (FN) in patients with stage II breast cancer receiving TC (docetaxel, cyclophosphamide) and in patients with non-Hodgkin lymphoma (NHL) receiving R-CHOP (rituximab, cyclophosphamide, doxorubicin, vincristine, prednisone) over a lifetime horizon from a Belgian payer perspective.
\end{abstract}

Electronic supplementary material The online version of this article (doi:10.1007/s40273-016-0474-0) contains supplementary material, which is available to authorized users.

Kelly Fust

kelly.fust@optum.com

1 Optum, 950 Winter St, Waltham, MA 02451, USA

2 Amgen Inc., One Amgen Center Drive, Thousand Oaks, CA 91320, USA

3 Optum, 5500 North Service Road, Suite 501, Burlington, ON L7L 6W6, Canada

4 Amgen (Europe) GmbH, Dammstrasse 23, Zug, Switzerland

5 Harvard T.H. Chan School of Public Health, 718 Huntington Avenue, Boston, MA 02115, USA

6 OncoLogX bvba, Arthur Boelstraat 66, 2990 Wuustwezel, Antwerp, Belgium

7 Amgen Belgium S.A., Avenue Ariane 5, 1200 Brussels, Belgium

8 Fred Hutchinson Cancer Research Center, 1100 Fairview Ave. N., Seattle, WA 98109, USA
Methods A Markov cycle tree tracked FN events during chemotherapy (3-week cycles) and long-term survival (1year cycles). Model inputs, including the efficacy of each strategy, risk of reduced relative dose intensity (RDI), and the impact of RDI on mortality, utilities, and costs (in €; 2014 values) were estimated from public sources and the published literature. Incremental cost-effectiveness ratios (ICERs) were assessed for each strategy for costs per FN event avoided, life-year (LY) saved, and quality-adjusted LY (QALY) saved. LYs and QALYs saved were discounted at $1.5 \%$ annually. Deterministic and probabilistic sensitivity analyses (DSAs and PSAs) were conducted.

Results Base-case ICERs for PP with pegfilgrastim relative to SP with pegfilgrastim were $€ 15,500$ per QALY and $€ 14,800$ per LY saved for stage II breast cancer and $€ 7800$ per QALY and $€ 6900$ per LY saved for NHL; other comparators were either more expensive and less effective than PP or SP with pegfilgrastim or had lower costs but higher ICERs (relative to SP with pegfilgrastim) than PP with pegfilgrastim. Results of the DSA for breast cancer and NHL comparing PP and SP with pegfilgrastim indicate that the model results were most sensitive to the cycle 1 risk of $\mathrm{FN}$, the proportion of FN events requiring hospitalization, the relative risk of $\mathrm{FN}$ in cycles $\geq 2$ versus cycle 1 , no history of $\mathrm{FN}$, and the mortality hazard ratio for RDI $(<90 \%$ vs $\geq 90 \%$ [for NHL]). In the PSAs for stage II breast cancer and NHL, the probabilities that PP with pegfilgrastim was cost effective or dominant versus all other prophylaxis strategies at a $€ 30,000 / \mathrm{QALY}$ willingness-to-pay threshold were 52\% (other strategies $\leq 24 \%$ ) and 58\% (other strategies $\leq 24 \%$ ), respectively.

Conclusion From a Belgian payer perspective, PP with pegfilgrastim appears cost effective compared to other prophylaxis strategies in patients with stage II breast cancer or NHL at a $€ 30,000 / \mathrm{QALY}$ threshold. 


\section{Key Points for Decision Makers}

In this model of febrile neutropenia in patients with stage II breast cancer or non-Hodgkin lymphoma, primary prophylaxis with pegfilgrastim appears cost effective as compared to other prophylaxis strategies at a $€ 30,000$ per quality-adjusted life-year threshold.

Compared with past models, this model used updated data from a meta-analysis for efficacy measures, included two cancer/chemotherapy scenarios, and added lipegfilgrastim as a treatment strategy.

\section{Introduction}

Febrile neutropenia (FN), defined as an absolute neutrophil count of $<0.5 \times 10^{9} / \mathrm{L}$, or $<1.0 \times 10^{9} / \mathrm{L}$ predicted to fall below $0.5 \times 10^{9} / \mathrm{L}$ within $48 \mathrm{~h}$, with fever or clinical signs of sepsis [1], is a serious adverse effect of chemotherapy and can result in significant morbidity, mortality, and costs $[2,3]$. FN is also associated with suboptimal delivery of chemotherapy and reduced relative dose intensity (RDI), which adversely affects long-term cancer outcomes and survival [4]. The risk of FN depends on both patientspecific factors (e.g., cancer type and stage, co-morbidities, and age) and the myelotoxicity of the chemotherapy regimen received [1].

Granulocyte colony-stimulating factors (G-CSFs) are indicated to reduce the duration of neutropenia and the incidence of FN in patients with non-myeloid malignancies receiving myelosuppressive chemotherapy associated with a clinically significant incidence of FN [5-8]. European clinical practice guidelines recommend prophylaxis with G-CSF when the risk of FN is high ( $>20 \%$ ) based on either chemotherapy regimen risk alone or a combination of regimen risk and individual patient risk factors [1]. While pegfilgrastim and lipegfilgrastim require only one administration per chemotherapy cycle, filgrastim and lenograstim require daily administration until neutrophil counts recover. Although an average of 10-11 doses of filgrastim or lenograstim per chemotherapy cycle were effective in clinical trials $[9,10]$, in clinical practice daily G-CSFs are sometimes administered in shorter courses (i.e., four to six doses), which can result in reduced effectiveness [11]. G-CSFs can be used as primary prophylaxis (PP) or secondary prophylaxis (SP); PP is defined as prophylactic administration in the first cycle and every subsequent cycle of chemotherapy, while SP is defined as initiation of prophylaxis in the cycle immediately after the first cycle with an FN event and continuing prophylaxis until the end of the chemotherapy course.

Previously, Markov models have been used to examine the cost effectiveness of FN prophylaxis strategies in patients with early-stage breast cancer [12, 13], recurrent ovarian cancer [14], and non-Hodgkin lymphoma (NHL) $[15,16]$. This model used updated data from a meta-analysis for efficacy measures [17], included two cancer/ chemotherapy scenarios, and added lipegfilgrastim as a treatment strategy. The cost effectiveness of lipegfilgrastim, which was approved by the European Medicines Agency in 2013 [7], has not been examined previously. Our model was developed from a Belgian payer perspective to estimate the cost effectiveness of no prophylaxis, $\mathrm{PP}$, and SP with pegfilgrastim, lipegfilgrastim, filgrastim (6- and 11-day courses), and lenograstim (6- and 11-day courses) in patients with stage II breast cancer receiving TC (docetaxel and cyclophosphamide) and patients with NHL receiving R-CHOP (rituximab, cyclophosphamide, doxorubicin, vincristine, and prednisone).

\section{Methods}

\subsection{Model Structure}

The model structure was adapted from previously published cost-effectiveness models in FN [12, 14-16] and includes clinically relevant elements (e.g., FN-related mortality and RDI) that are reflective of real-world clinical observations and practice. Both clinical and modeling experts were consulted during the model development process. More details on validation and testing of the conceptual model, data inputs, computational model, and operational validity are contained in the Technical Appendix in the Electronic Supplementary Material.

The Markov cycle tree was developed in Microsoft Excel $^{\circledR} 2010$ to simulate FN events, RDI, and survival in the treatment of stage II breast cancer patients receiving TC $\left(75 \mathrm{mg} / \mathrm{m}^{2}\right.$ of docetaxel and $600 \mathrm{mg} / \mathrm{m}^{2}$ of cyclophosphamide every 21 days for four cycles) and NHL patients receiving R-CHOP (cyclophosphamide $750 \mathrm{mg} /$ $\mathrm{m}^{2}$ on day 1 , doxorubicin $50 \mathrm{mg} / \mathrm{m}^{2}$ on day 1 , vincristine $1.4 \mathrm{mg} / \mathrm{m}^{2}$ on day 1 , prednisone $100 \mathrm{mg} /$ day on days $1-5$, plus rituximab $375 \mathrm{mg} / \mathrm{m}^{2}$ on day 1 every 21 days for six cycles). Initially, there was a decision whether to have no prophylaxis or to initiate PP or SP (Fig. 1). If prophylaxis was initiated, there was a decision as to which G-CSF to use, i.e., pegfilgrastim, filgrastim (6- or 11-day), lenograstim (6- or 11-day), or lipegfilgrastim. For each of these choices, there was a chance of FN occurring during the first chemotherapy cycle (cycle length $=3$ weeks; Fig. 1a). Following the decision tree, FN events were then 


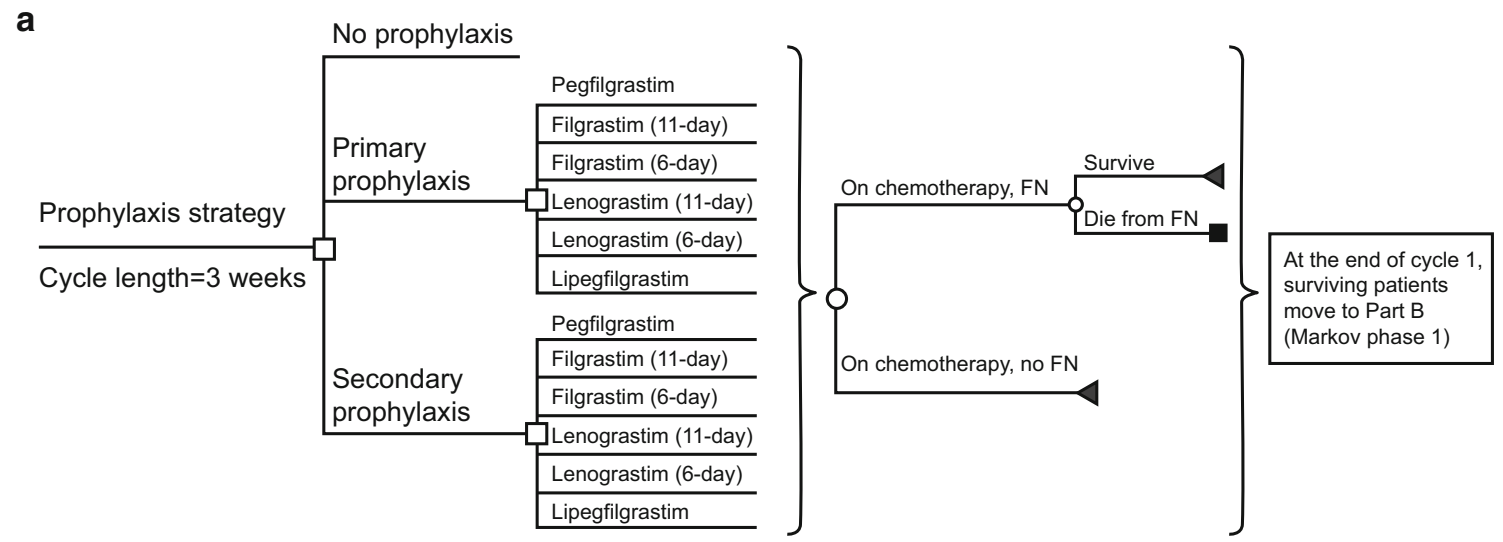

b

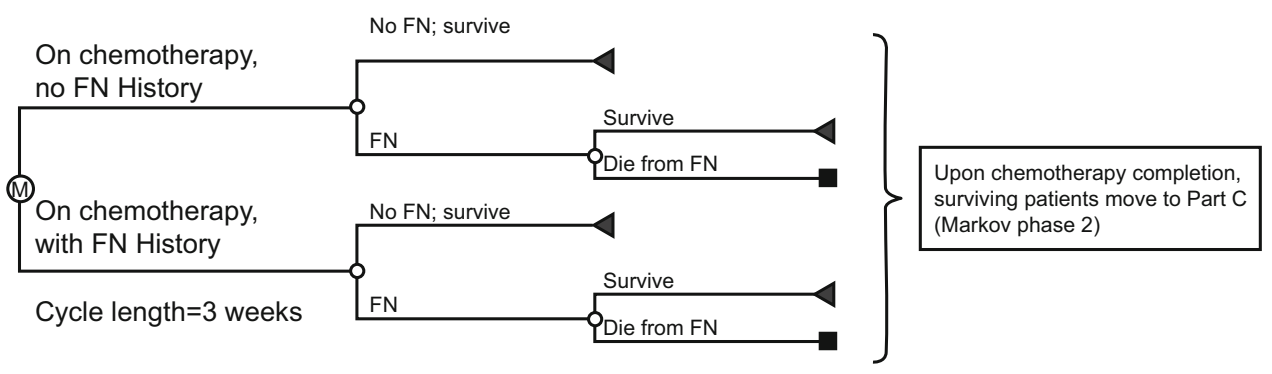

C

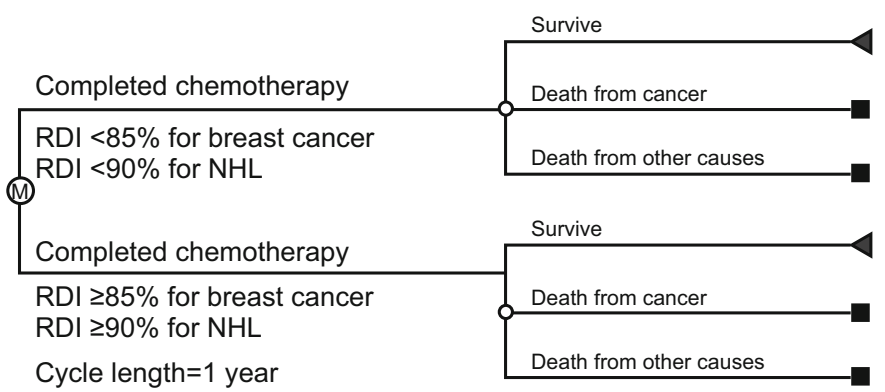

Fig. 1 Markov cycle tree with hypothetical cohorts of stage II breast cancer patients receiving TC for four cycles and non-Hodgkin lymphoma patients receiving R-CHOP for six cycles. Model structure: a decision tree (initial chemotherapy cycle and associated febrile neutropenia events); b Markov phase 1 (subsequent chemotherapy

tracked in chemotherapy cycles $2+$ (cycle length $=3$ weeks; Fig. 1b). After chemotherapy, longterm cancer-related survival was tracked in Markov cycles (cycle length $=1$ year; Fig. 1c). Patients were categorized by RDI of chemotherapy received. During each of these cycles, patients could transition to different health states, with each health state having a corresponding cost and quality-of-life outcome. Markov cycles were repeated for the lifetime of a patient; the model concluded when the entire cohort died. Total costs and outcomes were summed across cycles. Clinical inputs, costs (in euros $(€) ; 2014$ values), and utilities were estimated from peer-reviewed publications, publicly available sources, and research databases (Tables 1, 2). cycles after cycle 1); and c Markov phase 2 (post-chemotherapy period). $F N$ febrile neutropenia, $M$ Markov, $N H L$ non-Hodgkin lymphoma, $R$-CHOP rituximab, cyclophosphamide, doxorubicin, vincristine, and prednisone, $R D I$ relative dose intensity, $T C$ docetaxel and cyclophosphamide

\subsection{Model Inputs}

Model inputs were estimated based on data published in English in peer-reviewed journals or publicly available sources, as described in Sects. 2.2.1-2.2.6. We also used data sources consistent with previously published cost-effectiveness models of FN [12, 14-16].

\subsubsection{Febrile Neutropenia Risk}

In a meta-analysis of 902 breast cancer patients receiving TC from 13 studies, the pooled random-effects estimate of chemotherapy course-level FN risk without primary G-CSF prophylaxis was $29 \%$. The baseline FN risk in cycle 1 (19\%) was estimated by calibrating the model using Solver 
Table 1 Clinical parameters: granulocyte colony-stimulating factor efficacy and febrile neutropenia risk parameters for breast cancer and nonHodgkin lymphoma

\begin{tabular}{|c|c|c|}
\hline Clinical parameters & $\begin{array}{l}\text { Base-case efficacy value } \\
\text { RR vs. no G-CSF (DSA range) }\end{array}$ & PSA SE, distribution type \\
\hline \multicolumn{3}{|l|}{ Prophylaxis strategy } \\
\hline Pegfilgrastim $^{\mathrm{a}}$ [17] & $0.29(0.19-0.44)$ & $\begin{array}{l}\text { Log mean }=-1.25 \\
\quad \mathrm{SD}=0.21, \text { LogNormal }\end{array}$ \\
\hline Filgrastim (11-day) ${ }^{\mathrm{a}}[17]$ & $0.44(0.29-0.64)$ & $\begin{array}{l}\text { Log mean }=-0.82, \\
\quad \mathrm{SD}=0.20, \text { LogNormal }\end{array}$ \\
\hline Filgrastim (6-day) [11] & $0.71(0.37-1.00)$ & $\mathrm{SE}=0.17$, beta \\
\hline Lenograstim (11-day) $)^{\mathrm{a}}[17]$ & $0.59(0.39-0.81)$ & $\begin{array}{l}\log \text { mean }=-0.52 \\
\quad \mathrm{SD}=0.18, \text { LogNormal }\end{array}$ \\
\hline Lenograstim (6-day) [11] & $0.71(0.37-1.00)$ & $\mathrm{SE}=0.17$, beta \\
\hline Lipegfilgrastim $^{\mathrm{a}}$ [17] & $0.39(0.16-0.90)$ & $\begin{array}{l}\text { Log mean }=-0.94 \\
\quad \mathrm{SD}=0.44, \text { LogNormal }\end{array}$ \\
\hline No prophylaxis (baseline) & 1.00 (NA) & NA \\
\hline \multicolumn{3}{|l|}{ FN risk parameters } \\
\hline RR of FN in cycles $\geq 2$, history of FN vs. no history of FN $[13,53]$ & $9.09(6.19-13.35)$ & $\begin{array}{l}\log \text { mean }=2.21 \\
\quad \mathrm{SD}=0.20, \text { LogNormal }\end{array}$ \\
\hline RR of FN in cycles $\geq 2$ vs. cycle 1 , no history of FN $[13,53]$ & $0.21(0.155-0.293)$ & $\begin{array}{l}\log \text { mean }=-1.56 \\
\quad \mathrm{SD}=0.16, \text { LogNormal }\end{array}$ \\
\hline \multicolumn{3}{|l|}{ Breast cancer-specific parameters } \\
\hline Cycle 1 FN risk-TC [18] & $0.19(0.16-0.24)$ & $\mathrm{SE}=0.02$, beta \\
\hline $\begin{array}{l}\text { FN case-fatality (breast cancer) [2], SE based on average of Kuderer } \\
\text { et al. [3] and Dulisse et al. [54] (\%) }\end{array}$ & $3.4(2.7-4.1)$ & $\mathrm{SE}=0.0037$, beta \\
\hline Mortality HR for RDI $<85 \%$ vs. $\geq 85 \%$ (breast cancer) [24] & $1.45(1.00-2.32)^{\mathrm{b}}$ & $\begin{array}{l}\text { Log mean }=0.37 \\
\mathrm{SD}=0.215, \text { LogNormal }\end{array}$ \\
\hline $\begin{array}{l}\text { Proportion of FN events that require hospitalization (breast cancer) } \\
\text { [39] }\end{array}$ & $0.836(0.19-1.00)$ & $\mathrm{SE}=0.02$, beta \\
\hline $\begin{array}{l}\text { Probability of RDI }<85 \% \text {, age }<65 \text { years, no FN history (breast } \\
\text { cancer) [25] (\%) }\end{array}$ & 26.9 (NA) & NA \\
\hline OR for RDI $<85 \%$, age $\geq 65$ vs. $<65$ years (breast cancer) [25] & 1.51 (NA) & NA \\
\hline $\begin{array}{l}\text { OR for RDI }<85 \% \text {, history of FN vs. no history of FN [25], SE based } \\
\text { on number and } \%\end{array}$ & $1.58(1.18-2.07)$ & $\begin{array}{l}\text { Log mean }=0.457 \\
\quad \mathrm{SD}=0.143, \text { LogNormal }\end{array}$ \\
\hline Length of FN hospitalization (breast cancer) [3] (days) & $8.0(7.6-8.4)$ & NA \\
\hline Mean height (breast cancer) $[53](\mathrm{m})$ & $1.66(1.54-1.78)$ & $\mathrm{SD}=0.06$, normal \\
\hline Mean weight (breast cancer) [53] $(\mathrm{kg})$ & $69(41.6-96.4)$ & $\mathrm{SD}=14$, normal \\
\hline \multicolumn{3}{|l|}{ NHL-specific parameters } \\
\hline Cycle 1 FN risk-R-CHOP (assumed to be same as CHOP) [19] & $0.21(0.13,0.29)$ & $\mathrm{SE}=0.04$, beta \\
\hline $\begin{array}{l}\text { FN case-fatality (NHL) [2], SE from average of Kuderer et al. [3] and } \\
\text { Dulisse et al. [54] (\%) }\end{array}$ & $5.8(5.1-6.5)$ & $\mathrm{SE}=0.0034$, beta \\
\hline Mortality HR for RDI $<90 \%$ vs. $\geq 90 \%$ (NHL) [23] & $2.083(1.19-3.70)$ & $\begin{array}{l}\log \text { mean }=0.73 \\
\mathrm{SD}=0.29, \text { LogNormal }\end{array}$ \\
\hline Proportion of FN events that require hospitalization (NHL) [39] & $0.836(0.19-1.00)$ & $\mathrm{SE}=0.02$, beta \\
\hline Probability of RDI $<90 \%$, no FN history (NHL) [26] (\%) & $41.6(\mathrm{NA})$ & NA \\
\hline Probability of RDI <90\%, FN history (NHL) [26] (\%) & $70.6(58.1-83.1)$ & $\mathrm{SE}=0.064$, beta \\
\hline Length of FN hospitalization (NHL) [3] (days) & $10.7(10.4-11.0)$ & NA \\
\hline Mean height (NHL) [53] (m) & $1.72(1.60-1.85)$ & $\mathrm{SD}=0.06$, normal \\
\hline
\end{tabular}


Table 1 continued

\begin{tabular}{lll}
\hline Clinical parameters & $\begin{array}{l}\text { Base-case efficacy value } \\
\text { RR vs. no G-CSF (DSA range) }\end{array}$ & PSA SE, distribution type \\
\hline Mean weight (NHL) [53] (kg) & $74.94(45.4-104.5)$ & SD $=15.08$, normal
\end{tabular}

CHOP cyclophosphamide, doxorubicin, vincristine, and prednisone, DSAs deterministic sensitivity analyses, FN febrile neutropenia, $G$-CSF granulocyte colony-stimulating factor, $H R$ hazard ratio, $N A$ not applicable as not included in DSA and/or PSA (as denoted), $N H L$ non-Hodgkin lymphoma, $O R$ odds ratio, $P P$ primary prophylaxis, $P S A s$ probabilistic sensitivity analyses, $R$ - $C H O P$ rituximab, cyclophosphamide, doxorubicin, vincristine, and prednisone, $R D I$ relative dose intensity, $R R$ relative risk, $S D$ standard deviation, $S E$ standard error, $T C$ docetaxel and cyclophosphamide

${ }^{a}$ For the base case, median values were obtained from Wang et al. [17]; for the PSA, the 95\% confidence interval was used (e.g., for lipegfilgrastim vs. pegfilgrastim OR). For Wang et al. [17], a mixed-treatment comparison was used to assess the relative efficacy of PP with different G-CSFs to reduce the incidence of FN in cancer patients who received myelosuppressive chemotherapy in 30 randomized controlled trials published from 1990 to 2013

${ }^{\mathrm{b}}$ Lower bound truncated at 1.00

in Microsoft Excel $^{\circledR}$, where the absolute difference between the model-predicted risk at the end of four cycles and the risk of FN over the course of the study described in Younis et al. [18] was minimized. The FN risks in subsequent chemotherapy cycles (cycles 2-4) were calculated by applying relative risks (RRs) of FN involving FN history in any cycle(s) prior to the current cycle (described below).

Due to an absence of data for R-CHOP, the baseline FN risk of R-CHOP in NHL in cycle 1 was assumed to be equivalent to CHOP (cyclophosphamide, doxorubicin, vincristine, and prednisone) (21\%), as based on a study of elderly patients with aggressive NHL in which 205 patients received CHOP $[16,19]$. In the model, it was assumed that $54 \%$ of the NHL population was male [16].

The RRs of FN in subsequent chemotherapy cycles (i.e., cycles 2+) were obtained from Whyte et al. [13], as estimated based on data for breast cancer patients [11]. The $\mathrm{RR}$ of FN in cycles $2+$ versus cycle 1 for patients with no FN history was 0.21 , and the RR of FN in cycles $2+$ for patients with an FN history versus no FN history was 9.09.

\subsubsection{Efficacy with Granulocyte Colony-Stimulating Factor Strategies}

The base-case efficacy rates for pegfilgrastim, filgrastim (11-day), lenograstim (11-day), and lipegfilgrastim were obtained from a meta-analysis [17], with odds ratios (ORs) converted to RRs (relative to no G-CSF prophylaxis) (Table 1). In the meta-analysis [17], a mixed-treatment comparison was used to assess the relative efficacy of PP with different G-CSFs to reduce the incidence of FN in cancer patients who received myelosuppressive chemotherapy in 30 randomized controlled trials published from 1990 to 2013. Efficacy estimates for filgrastim (6day) and lenograstim (6-day) relative to pegfilgrastim were obtained from von Minckwitz et al. [11], in which data for filgrastim (6-day) and lenograstim (6-day) were combined; accordingly, efficacy estimates for 6-day filgrastim and 6-day lenograstim were assumed to be equivalent. For patients with no history of $\mathrm{FN}$, the risk of $\mathrm{FN}$ in chemotherapy cycles $2+$ was calculated as the baseline cycle 1 probability of $\mathrm{FN}$, reduced when applicable by the relative efficacy of prophylaxis, and multiplied by the cycle $2+$ RR $(0.21)$. For those patients with a history of FN, this value was further multiplied by the FN history risk multiplier (9.09).

\subsubsection{Mortality Risk}

During the on-chemotherapy phase of the model, patients were assumed to be at risk of death from FN only, not from cancer or other causes. FN case-fatality rates for breast cancer $(3.4 \%)$ and NHL (5.8\%) were obtained from Caggiano et al. [2]. In the absence of data regarding the longterm mortality due to breast cancer and NHL in Belgium, data from the Netherlands Cancer Registry Database $[20,21]$ were used to estimate the cancer-specific postchemotherapy mortality for years $1-10$. Mortality rates for years 11-20 were extrapolated by fitting the available data to an exponential curve and applying the resulting constant annual mortality rate. Patients alive 20 years after chemotherapy were considered 'cured' and were subsequently subject to the same all-cause mortality rates as those for the general population as per 2014 Belgian life tables [22].

\subsubsection{Relative Dose Intensity}

Following completion of chemotherapy, patients were stratified based on the RDI of chemotherapy received. RDI thresholds of $85 \%$ for breast cancer and $90 \%$ for NHL were selected as clinical data indicate that these are clinically meaningful reductions in the delivered chemotherapy dose intensity [23, 24]. The probabilities of an RDI $<85 \%$ and $\geq 85 \%$ for breast cancer and of an RDI $<90 \%$ and $\geq 90 \%$ for NHL depended on whether the patient experienced an 
Table 2 Costs for prophylaxis strategies and chemotherapy and utilities for breast cancer and non-Hodgkin lymphoma

\begin{tabular}{|c|c|c|}
\hline & Base-case value (DSA range) & PSA SE, distribution type \\
\hline \multicolumn{3}{|l|}{ Prophylaxis cost ${ }^{\mathrm{a}}$} \\
\hline Pegfilgrastim (6 mg injection) ${ }^{\mathrm{b}}(€)$ & 1176.03 & \multirow[t]{8}{*}{ NA } \\
\hline Filgrastim $(300 \mu \mathrm{g})^{\mathrm{b}}(€)$ & 60.036 & \\
\hline Filgrastim $(480 \mu \mathrm{g})^{\mathrm{b}}(€)$ & 83.964 & \\
\hline Lenograstim $(263 \mu \mathrm{g})^{\mathrm{b}}(€)$ & 76.038 & \\
\hline $\operatorname{Lipegfilgrastim}^{\mathrm{c}}(€)$ & 1176.03 & \\
\hline 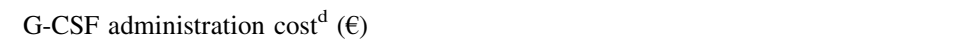 & $6.22\left(5.60-6.84^{\mathrm{h}}\right)$ & \\
\hline $\mathrm{CBC} \operatorname{cost}^{\mathrm{d}}(€)$ & $9.32\left(8.39-10.25^{\mathrm{h}}\right)$ & \\
\hline Percentage self-administering [38] (\%) & $20(0-40)$ & \\
\hline \multicolumn{3}{|l|}{ Breast cancer-costs and utility values } \\
\hline \multicolumn{3}{|l|}{$\operatorname{Costs}^{\mathrm{e}}$} \\
\hline TC chemotherapy $\operatorname{cost}^{\mathrm{f}}(€)$ & $519.09\left(467-571^{\mathrm{h}}\right)$ & \multirow[t]{4}{*}{ NA } \\
\hline Breast cancer FN hospitalization cost [37] (€) & $5317\left(4785-5849^{\mathrm{h}}\right)$ & \\
\hline Breast cancer post-hospitalization FN cost [42] & $32 \%$ of inpatient $\left(1531-1872^{\mathrm{h}}\right)$ & \\
\hline Breast cancer outpatient FN cost [39] & $16 \%$ of inpatient $\left(766-936^{\mathrm{h}}\right)$ & \\
\hline \multicolumn{3}{|l|}{ Utility values } \\
\hline On chemotherapy $[27]^{\mathrm{g}}$ & $0.70\left(0.55-0.83^{\mathrm{j}}\right)$ & $\mathrm{SE}=0.07$, beta $^{\mathrm{j}}$ \\
\hline FN hospitalization, average of Brown and Hutton [30] and Brown et al. [31] & $0.33\left(0.27-0.40^{j}\right)$ & $\mathrm{SE}=0.03$, beta $^{\mathrm{j}}$ \\
\hline Post-chemotherapy, years 1-5 [33] & $0.86\left(0.65-0.98^{\mathrm{j}}\right)$ & $\mathrm{SE}=0.09$, beta $^{\mathrm{j}}$ \\
\hline Post-chemotherapy, years $5+[34,35]$ & $0.96\left(0.83-1.00^{\mathrm{k}}\right)$ & $\mathrm{SE}=0.05$, beta $^{\mathrm{k}}$ \\
\hline \multicolumn{3}{|l|}{ NHL_costs and utility values } \\
\hline \multicolumn{3}{|l|}{$\operatorname{Costs}^{\mathrm{e}}$} \\
\hline R-CHOP chemotherapy $\operatorname{cost}^{\mathrm{f}}(€)$ & $1794.86\left(1615-1974^{\mathrm{h}}\right)$ & \multirow[t]{4}{*}{ NA } \\
\hline NHL FN hospitalization cost [38] (€) & $7183\left(6465-7901^{\mathrm{h}}\right)$ & \\
\hline NHL post-hospitalization FN cost [42] & $32 \%$ of inpatient $\left(€ 2069-€ 2528^{\mathrm{h}}\right)$ & \\
\hline NHL outpatient FN cost [39] & $16 \%$ of inpatient $\left(€ 1034-€ 1264^{\mathrm{h}}\right)$ & \\
\hline \multicolumn{3}{|l|}{ Utility values } \\
\hline NHL on chemotherapy $[28,29]^{\mathrm{i}}$ & $0.61\left(0.49-0.73^{\mathrm{j}}\right)$ & $\mathrm{SE}=0.06$, beta $^{\mathrm{j}}$ \\
\hline NHL FN hospitalization, average of Brown and Hutton [30] and Brown et al. [31] & $0.33\left(0.27-0.40^{j}\right)$ & $\mathrm{SE}=0.03$, beta $^{\mathrm{j}}$ \\
\hline NHL post-chemotherapy, year 1 [29] & $0.79\left(0.62-0.92^{\mathrm{j}}\right)$ & $\mathrm{SE}=0.08$, beta $^{\mathrm{j}}$ \\
\hline NHL post-chemotherapy, years $2+[29]$ & $0.89\left(0.79-0.96^{\mathrm{k}}\right)$ & $\mathrm{SE}=0.04$, beta $^{\mathrm{k}}$ \\
\hline
\end{tabular}

Unless otherwise indicated, the DSA range is based on $95 \%$ confidence intervals

$B S A$ body surface area, $C B C$ complete blood count, $D S A s$ deterministic sensitivity analyses, $F N$ febrile neutropenia, $G$-CSF granulocyte colony-stimulating factor, $N A$ not applicable as not included in the PSA, NHL non-Hodgkin lymphoma, NIHDI National Institute for Health and Disability Insurance, PSAs probabilistic sensitivity analyses, $R$ - $C H O P$ rituximab, cyclophosphamide, doxorubicin, vincristine, and prednisone, $S D$ standard deviation, $S E$ standard error, TC docetaxel and cyclophosphamide

${ }^{\text {a }}$ Filgrastim and lenograstim dosing is based on patient height and weight, with mean heights and weights of breast cancer and NHL patients calculated from the studies in a meta-analysis [53]. Based on the mean height, weight, and a correlation coefficient of 0.50 , a Dubois distribution was used to simulate the proportion of patients with weights by cut points $(60,96$, and $120 \mathrm{~kg})$ and BSA $<1.8$ and $\geq 1.8 \mathrm{~m}^{2}$. Patients weighing $<60,60-96,96-120$, and $>120 \mathrm{~kg}$ were assumed to receive filgrastim $300,480,600$, and $780 \mu \mathrm{g}$, respectively. Patients with BSA $<1.8 \mathrm{~m}^{2}$ were assumed to receive one vial of lenograstim $263 \mu \mathrm{g}$, and those with BSA $\geq 1.8 \mathrm{~m}^{2}$ were assumed to receive two vials of lenograstim $263 \mu \mathrm{g}$

${ }^{\mathrm{b}}$ NIHDI chapter 4 list prices, April 2014

c NIHDI chapter 4 list prices, August 2014

${ }^{\mathrm{d}}$ NIHDI NomenSoft 2013

e The base-case FN hospitalization cost reflected the cost of FN-related hospitalization episodes for patients with breast cancer or NHL in Belgium [37, 38]. The post-hospitalization cost, reflecting ambulatory services, was calculated as $32 \%$ of the initial hospitalization cost [42]. FN events not requiring hospitalization were assumed to be $16 \%$ of the FN hospitalization cost [39]

${ }^{\mathrm{f}}$ Weighted average based on NIHDI chapter 4 list prices, March 2014

$\mathrm{g}$ The base-case utility estimate for breast cancer patients receiving chemotherapy was obtained from a focus group of oncology physician and nursing staff using the visual analog scale

${ }^{\text {h }}$ DSA range is $90-110 \%$ of base-case value

i The base-case utility estimate for NHL patients was obtained from the European Quality of Life 5-Dimension (EQ-5D) questionnaire

${ }^{j} \mathrm{SE} / \mathrm{SD}$ not reported by studies; the range is based on assumption (assumed SE of $10 \%$ of base-case value)

${ }^{k} \mathrm{SE} / \mathrm{SD}$ not reported by studies; the range is based on assumption (assumed SE of $5 \%$ of base-case value) 
FN event during chemotherapy (Shayne et al. [25] and Pettengell et al. [26], respectively), and also depended on age for breast cancer [25]. Data from a study of women with early-stage breast cancer were used to estimate the mortality hazard ratio (HR) for patients with an RDI $<85 \%$ $(H R=1.45)$ [24]. The HR for NHL patients was based on data for CHOP [23], for which there was an HR of 0.48 for an average RDI of $\geq 90 \%$ versus $<90 \%$; the reciprocal HR of 2.08 was used in the model. Separate annual probabilities of death were calculated for those with an RDI $\geq 85 \%$ / $90 \%$ and $<85 \% / 90 \%$, with weighted averages equal to the overall mortality probabilities from the Netherlands Cancer Registry Database [20, 21]. The HRs for mortality, 1.45 (breast cancer) and 2.08 (NHL), were subsequently applied to patients with an RDI $<85 \%$ (breast cancer) and $<90 \%$ (NHL) only.

\subsubsection{Utilities}

To calculate quality-adjusted life-years (QALYs), lifeyears (LYs) were adjusted using utility values. Utility values for chemotherapy, FN, and FN-related hospitalization were estimated for consistency with Lyman et al. $[12,15]$. The base-case utility estimate for breast cancer patients receiving chemotherapy was obtained from an oncology physician and nursing staff focus group using the visual analog scale (VAS) [27]. The base-case utility estimate for NHL patients receiving chemotherapy was obtained from Doorduijn et al. [28] and Uyl-de Groot et al. [29]; these studies were conducted in The Netherlands/ Belgium, and the utilities were based on the European Quality of Life-5 Dimension (EQ-5D) questionnaire. The utilities associated with FN hospitalization for the breast cancer and NHL analyses were estimated as an average of Brown and Hutton [30] and Brown et al. [31] (estimates of 0.42 and 0.24 , respectively, in breast cancer patients) and were obtained from surveys of oncology nurses in the US and UK, respectively, using the standard gamble technique. In the model, this value is applied for the duration of FN hospitalization ( 8 days for breast cancer and 10.7 days for NHL as per Kuderer et al. [3]). An alternative analysis incorporated an estimate from Lloyd et al. [32], who suggest that the utility decrement of FN is 0.15 ; the utility of FN was calculated by subtracting 0.15 from the baseline utility of having cancer and receiving chemotherapy $(0.70$ for stage II breast cancer and 0.61 for NHL).

Patients were also assigned post-chemotherapy longterm utilities in the first and subsequent years; breast cancer estimates were based on a US study in which utility values were assigned to each health state in the Armstrong model by 30 internists [33]. Data obtained from Liljegren et al. [34] and de Haes et al. [35] were used to estimate the postchemotherapy utility in years $5+$ for breast cancer patients; health states were valued by 27 health professionals (including 12 breast cancer experts) using the VAS; the estimate represents the utility of being disease-free $>1$ year after breast-conserving therapy. Consistent with Lyman et al. [15] in the NHL analyses, the postchemotherapy utility estimates were obtained from Uyl-de Groot et al. [29] and were also based on the EQ-5D questionnaire.

\subsubsection{Costs}

All costs are presented in $2014(€)$; cost estimates were inflated to 2014 values using the official Belgian Health Index. Where possible, official published prices were used. For drug costs, the official prices in the ambulatory setting were used, as published on the website of the Belgian Federal Institute for Sickness and Invalidity Insurance (http://www.riziv.fgov.be/). For medical services such as the administration of drugs or laboratory tests (e.g., complete blood count $[\mathrm{CBC}]$ ), costs were also used as available on the same website. Costs related to hospitalization for FN treatment are from previous publications and were based on data from Moeremans et al. [36] as actualized in Somers et al. [37] (costs for treating FN in breast cancer patients in Belgium) and in Verhoef et al. [38] (costs for treating FN in NHL patients in Belgium). For the readers' information, these three references have been included in a Technical Appendix in the Electronic Supplementary Material. Costs described in Moeremans et al. [36] included costs for hospitalization, use of antimicrobials, infusions, laboratory tests, interventions, and other medications. Drug acquisition and other costs are listed in Table 2. These drug acquisition costs included a small capped margin for pharmacy costs of preparation and delivery. Pegfilgrastim was assumed to be administered once per chemotherapy cycle, and patients were assumed to receive one $\mathrm{CBC}$ the day before each chemotherapy cycle began [5]. For filgrastim, the summary of product characteristics (SPC) [6] recommends one $\mathrm{CBC}$ prior to chemotherapy and two per week during filgrastim therapy; thus, 6-day filgrastim was associated with three CBCs, and 11-day filgrastim was associated with five CBCs. Lenograstim was assumed to have the same CBC schedule as filgrastim. The SPC for lipegfilgrastim [7] indicates that a white blood cell count should be performed at regular intervals during therapy; it was assumed that lipegfilgrastim was associated with one CBC prior to chemotherapy and one $\mathrm{CBC}$ during each chemotherapy cycle. It was estimated that $20 \%$ of patients self-administered [38]; these patients accordingly did not incur administration costs. It was also estimated that $83.6 \%$ of FN cases would require hospitalization in both the breast cancer and NHL analyses [39]. Although two US studies $[39,40]$ report that approximately $83 \%$ of $\mathrm{FN}$ events 
require hospitalization, Gerlier et al. [41] estimated that $19 \%$ of FN episodes for patients receiving PP required hospitalization based on estimates from clinical experts in Belgium. Accordingly, a lower bound of $19 \%$ for the percentage of FN events requiring hospitalization was used in the deterministic sensitivity analysis (DSA).

FN cost estimates were based on two original resources: the Moeremans et al. [36] 2005 study with a chart review of FN hospitalization costs in Belgium and the All Patient Refined Diagnosis-Related Group (APR-DRG) 660 costs obtained from the official source (http://www.tct.fgov.be), both actualized to 2014 costs. These source data have also been described in two previous studies [37, 38]. Specifically, the base-case FN hospitalization cost reflected the cost of FN-related hospitalization episodes for patients with breast cancer or NHL in Belgium [37, 38]. For outpatient FN and post-hospitalization costs, as specific Belgian costs were not available, proportional cost estimates in comparison to FN hospitalization costs from the USA $[39,42]$ were used as the best-referenced estimates available. The post-hospitalization cost, reflecting ambulatory services, was calculated as $32 \%$ of the initial hospitalization cost [42]. FN events not requiring hospitalization were assumed to be $16 \%$ of the FN hospitalization cost [39].

\subsection{Analyses}

All analyses were performed from the payer perspective and therefore included direct healthcare costs only. Expected lifetime costs (excluding cancer care costs other than those specified as being included, e.g. chemotherapy, hospitalization, etc.), LYs, and QALYs were estimated for each strategy. Cost effectiveness was assessed in terms of incremental cost per FN event avoided, incremental cost per LY saved, and incremental cost per QALY saved. Per the Belgian guidelines, LYs and QALYs were discounted at a rate of $1.5 \%$ per year [43]. Alternative analyses were performed using discount rates of 0 and 3\%, reflecting recommendations by health technology assessment (HTA) authorities in other European countries [43, 44]. The discount rate for costs in Belgium is 3\% [43]; however, since all costs were incurred in the first year of the model, costs were not discounted in model analyses. A half-cycle correction was used [45].

If a more costly strategy provided no additional benefit compared with an alternative strategy (i.e., was both more costly and less effective), then it was said to be 'dominated' by the alternative strategy, and no incremental costeffectiveness ratio (ICER) was calculated. If a more costly strategy provided additional benefit, then the two strategies were compared by dividing the additional cost (i.e., incremental cost) by the additional benefit (i.e., incremental effectiveness). Weak dominance (or extended dominance) occurred when the ICER for a strategy was greater than that of a more costly alternative. Strategies that were weakly dominated were excluded, and ICERs of the remaining strategies were recalculated. The process of exclusion and recalculation was repeated until no remaining strategies were weakly dominated [45]. A willingnessto-pay threshold of $€ 30,000 / \mathrm{QALY}$ was used as the criterion for acceptable cost effectiveness [46].

\subsubsection{Sensitivity Analyses}

One-way sensitivity analyses were performed only for the cost-effectiveness analysis, with QALYs as the outcome measure. For DSAs, key model parameters were varied using $95 \%$ confidence intervals (CIs), standard errors, and plausible ranges derived from published literature (Tables 1,2) to assess how univariate changes in key model parameters and parameter uncertainty impacted cost-effectiveness results. In addition to the DSAs, a scenario analysis was performed using an alternative data source for the baseline risk of FN (23.2\%) [47].

Uncertainty in cost-effectiveness results was also assessed by performing probabilistic sensitivity analyses (PSAs) using second-order Monte Carlo simulations. Uncertainty in key model parameters (e.g., efficacy, baseline risk and RR of FN, RDI parameters, costs, and utilities) was characterized by probability distributions around the base-case values for each parameter. Parameters of these distributions were derived from the published literature, or plausible ranges were formulated when CIs or ranges were not reported (Tables 1,2). A random number generator was used to draw parameter sets from each distribution, and these sets were run through the model to generate estimates of cost and effectiveness for each treatment strategy. The process of drawing parameters and running the model was repeated 1000 times. The incremental cost per QALY was then calculated for each set of parameter values as in the base case. PSA results are presented in the form of cost-effectiveness acceptability curves, which show the fractions of the 1000 simulations in which examined strategies were incrementally cost effective over a range of willingness-to-pay thresholds. Of note, the PSA was first conducted using a beta distribution with a 95\% CI of $0.19-1.00$ for the proportion of FN events requiring hospitalization. To further explore the uncertainty in the proportion of FN events requiring hospitalization, an alternative PSA was then performed using a uniform distribution assuming lower and upper bounds of 0.19 and 1 . 


\section{Results}

\subsection{Base-Case Analyses}

In patients with stage II breast cancer treated with TC, total costs per patient ranged from $€ 5037$ (SP with pegfilgrastim) to $€ 9005$ (PP with 11-day lenograstim; Table 3). The total number of FN events per patient ranged from 0.11 (PP with pegfilgrastim) to 0.53 (no prophylaxis). The total number of LYs ranged from 15.92 (no prophylaxis) to
16.18 (PP with pegfilgrastim), and the total number of QALYs ranged from 15.01 (no prophylaxis) to 15.26 (PP with pegfilgrastim). The ICERs for PP with pegfilgrastim versus SP with pegfilgrastim were $€ 9700$ per FN event avoided, $€ 14,800$ per LY saved, and $€ 15,500$ per QALY saved. Other comparators were either dominated by PP or SP with pegfilgrastim or eliminated via extended dominance.

In patients with NHL treated with R-CHOP, total costs per patient ranged from $€ 16,387$ (SP with pegfilgrastim) to

Table 3 Base-case cost-effectiveness results for stage II breast cancer treated with TC (docetaxel and cyclophosphamide) (incremental cost per febrile neutropenia event avoided, life-years saved, and quality-adjusted life-years saved) versus secondary prophylaxis with pegfilgrastim

\begin{tabular}{llllllll}
\hline Prophylaxis strategy & $\begin{array}{l}\text { Total } \\
\text { costs }(€)\end{array}$ & $\begin{array}{l}\text { Total FN } \\
\text { events }\end{array}$ & $\begin{array}{l}\text { Total } \\
\text { LYs }\end{array}$ & $\begin{array}{l}\text { Total } \\
\text { QALYs }\end{array}$ & $\begin{array}{l}\text { ICER }(\Delta \cos / \Delta \text { FN }) \\
\text { ICER }(\Delta \text { cost/ } \Delta \text { LY })\end{array}$ & $\begin{array}{l}\text { ICER }(\Delta \text { cost/ } \Delta \\
\text { QALYs })\end{array}$ \\
\hline SP with pegfilgrastim & 5037 & 0.361 & 16.014 & 15.099 & Ref & Ref & Ref \\
SP with lipegfilgrastim & 5226 & 0.386 & 16.001 & 15.085 & Dominated & Dominated & Dominated \\
SP with filgrastim (11-day) & 5252 & 0.398 & 15.994 & 15.079 & Dominated & Dominated & Dominated \\
SP with filgrastim (6-day) & 5287 & 0.463 & 15.959 & 15.045 & Dominated & Dominated & Dominated \\
No prophylaxis & 5340 & 0.534 & 15.920 & 15.008 & Dominated & Dominated & Dominated \\
SP with lenograstim (6-day) & 5412 & 0.463 & 15.959 & 15.045 & Dominated & Dominated & Dominated \\
SP with lenograstim (11-day) & 5705 & 0.436 & 15.974 & 15.059 & Dominated & Dominated & Dominated \\
PP with filgrastim (6-day) & 6233 & 0.334 & 16.040 & 15.123 & Extended dominance & Extended dominance & Extended dominance \\
PP with lenograstim (6-day) & 6992 & 0.334 & 16.040 & 15.123 & Dominated & Dominated & Dominated \\
PP with filgrastim (11-day) & 7117 & 0.182 & 16.133 & 15.213 & Extended dominance & Extended dominance & Extended dominance \\
PP with pegfilgrastim & 7482 & 0.109 & 16.179 & 15.257 & $€ 9735$ & E14,832 & $€ 15,459$ \\
PP with lipegfilgrastim & 7806 & 0.158 & 16.148 & 15.227 & Dominated & Dominated & Dominated \\
PP with lenograstim (11-day) & 9005 & 0.266 & 16.081 & 15.163 & Dominated & Dominated & Dominated \\
\hline
\end{tabular}

$\triangle$ incremental, $F N$ febrile neutropenia, ICER incremental cost-effectiveness ratio, $L Y S$ life-years, $P P$ primary prophylaxis, $Q A L Y$ quality-adjusted life-year, Ref reference strategy, $S P$ secondary prophylaxis

Table 4 Base-case cost-effectiveness results for non-Hodgkin lymphoma treated with R-CHOP (rituximab, cyclophosphamide, doxorubicin, vincristine, and prednisone) (incremental cost per febrile neutropenia event avoided, life-years saved, and quality-adjusted life-years saved)

\begin{tabular}{llllllll}
\hline Prophylaxis strategy & $\begin{array}{l}\text { Total } \\
\text { costs }(€)\end{array}$ & $\begin{array}{l}\text { Total FN } \\
\text { events }\end{array}$ & $\begin{array}{l}\text { Total } \\
\text { LYs }\end{array}$ & $\begin{array}{l}\text { Total } \\
\text { QALYs }\end{array}$ & $\begin{array}{l}\text { ICER }(\Delta \operatorname{cost} / \Delta \text { FN }) \\
\text { ICER }(\Delta \text { cost/ } \Delta \text { LY })\end{array}$ & $\begin{array}{l}\text { ICER }(\Delta \operatorname{cost} / \Delta \\
\text { QALYs })\end{array}$ \\
\hline SP with pegfilgrastim & 16,387 & 0.522 & 6.925 & 5.944 & Ref & Ref & Ref \\
SP with lipegfilgrastim & 16,858 & 0.576 & 6.905 & 5.927 & Dominated & Dominated & Dominated \\
SP with filgrastim (11-day) & 16,911 & 0.600 & 6.897 & 5.919 & Dominated & Dominated & Dominated \\
SP with filgrastim (6-day) & 17,312 & 0.736 & 6.847 & 5.875 & Dominated & Dominated & Dominated \\
SP with lenograstim (6-day) & 17,554 & 0.736 & 6.847 & 5.875 & Dominated & Dominated & Dominated \\
No prophylaxis & 17,747 & 0.882 & 6.795 & 5.829 & Dominated & Dominated & Dominated \\
SP with lenograstim (11-day) & 17,968 & 0.679 & 6.868 & 5.894 & Dominated & Dominated & Dominated \\
PP with filgrastim (6-day) & 18,170 & 0.538 & 7.024 & 6.031 & Dominated & Extended dominance & Extended dominance \\
PP with filgrastim (11-day) & 18,862 & 0.282 & 7.221 & 6.205 & Extended dominance & Extended dominance & Extended dominance \\
PP with pegfilgrastim & 19,149 & 0.164 & 7.327 & 6.299 & $€ 7724$ & €6865 & $€ 7782$ \\
PP with lenograstim (6-day) & 19,297 & 0.538 & 7.024 & 6.031 & Dominated & Dominated & Dominated \\
PP with lipegfilgrastim & 19,801 & 0.243 & 7.255 & 6.235 & Dominated & Dominated & Dominated \\
PP with lenograstim (11-day) & 22,007 & 0.423 & 7.109 & 6.106 & Dominated & Dominated & Dominated \\
\hline
\end{tabular}

$\triangle$ incremental, $F N$ febrile neutropenia, $I C E R$ incremental cost-effectiveness ratio, $L Y s$ life-years, $P P$ primary prophylaxis, $Q A L Y$ quality-adjusted life-year, Ref reference strategy, SP secondary prophylaxis 
$€ 22,007$ (PP with 11-day lenograstim; Table 4). The total number of FN events per patient ranged from 0.16 (PP with pegfilgrastim) to 0.88 (no prophylaxis). The total number of LYs ranged from 6.80 (no prophylaxis) to 7.33 (PP with pegfilgrastim), and the total number of QALYs ranged from 5.83 (no prophylaxis) to 6.30 (PP with pegfilgrastim). ICERs for PP with pegfilgrastim versus SP with pegfilgrastim were $€ 7700$ per FN event avoided, €6900 per LY saved, and $€ 7800$ per QALY saved. Other comparators were either dominated by PP or SP with pegfilgrastim or eliminated via extended dominance.

\subsection{Deterministic and Probabilistic Sensitivity Analyses}

DSAs were performed to determine which inputs the model results were most sensitive to. For the DSA for stage II breast cancer treated with TC (Fig. 2a), comparing PP pegfilgrastim with SP pegfilgrastim, the model results were most sensitive to cycle 1 risk of $\mathrm{FN}$ (ICER range $€ 9500-22,200$ ), proportion of FN events requiring hospitalization (€13,900-21,800), and RR of FN in cycles $\geq 2$ versus Cycle 1 (no history of FN) (€11,700-19,100). Similar results were seen in the DSA for NHL treated with R-CHOP (Fig. 2b); the model results were most sensitive to cycle 1 risk of $\mathrm{FN}(€ 2200-19,500)$, mortality HR for an RDI $<90 \%$ versus $\geq 90 \%$ (€5700-13,300), and proportion of FN events requiring hospitalization (€6400-13,200). Results from the analyses based on an alternative data source for the disutility of FN and with discount rates ranging from 0 to $3 \%$ were similar to the base case. Using an alternative data source for the probability of FN for the TC regimen [47] resulted in an increase in the ICER for PP with pegfilgrastim (vs. SP with pegfilgrastim) from $€ 15,500$ to $€ 24,100$ per QALY.

We next performed PSA to examine the probabilities that various prophylaxis strategies were cost effective. In the PSA for stage II breast cancer treated with TC (Fig. 2c), at a $€ 30,000 / \mathrm{Q} A L Y$ willingness-to-pay threshold, the probability that PP with pegfilgrastim was cost effective or dominant versus all other prophylaxis strategies was $52.0 \%$. The probabilities for other strategies were $23.6 \%$ for PP lipegfilgrastim, $14.0 \%$ for PP filgrastim 11-day, and $7.5 \%$ for PP filgrastim 6-day; all other strategies had probabilities $<3 \%$. Similarly, in PSA of NHL treated with R-CHOP (Fig. 2d), at a €30,000/QALY willingness-to-pay threshold, the probability that PP with pegfilgrastim was cost effective or dominant versus all other prophylaxis strategies was $57.8 \%$. The probabilities for other strategies were $23.9 \%$ for PP lipegfilgrastim, $12.0 \%$ for PP filgrastim 11-day, and $4.7 \%$ for PP filgrastim 6-day; all other strategies had probabilities $<2 \%$. Results of the PSA performed using a uniform distribution
4Fig. 2 Deterministic and probabilistic sensitivity analyses. a DSA results for stage II breast cancer, TC (PP with pegfilgrastim vs. SP with pegfilgrastim). b DSA results for NHL, R-CHOP (PP with pegfilgrastim vs. SP with pegfilgrastim). In $\mathbf{a}$ and $\mathbf{b}$, the vertical line represents the base-case ICER, and the horizontal bars represent the ranges of ICERs generated when the model was run using parameter values between the high and low values of the plausible range for each input considered. c PSA: cost-effectiveness acceptability curves for stage II breast cancer, TC. d PSA: cost-effectiveness acceptability curves for NHL, R-CHOP. In $\mathbf{c}$ and $\mathbf{d}$, the willingness-to-pay threshold in terms of $€ /$ QALY. $€$ euros, $B C$ base-case, $D S A$ deterministic sensitivity analysis, $F N$ febrile neutropenia event, $H R$ hazard ratio, ICER incremental cost-effectiveness ratio, $N H L$ nonHodgkin lymphoma, $O R$ odds ratio, $P P$ primary prophylaxis, $P S A$ probabilistic sensitivity analysis, $Q A L Y$ quality-adjusted life-year, $R$ $C H O P$ rituximab, cyclophosphamide, doxorubicin, vincristine, and prednisone, $R D I$ relative dose intensity, $R R$ relative risk, $S P$ secondary prophylaxis, $T C$ docetaxel and cyclophosphamide

(assuming lower and upper bounds of 0.19 and 1) for the proportion of $\mathrm{FN}$ events requiring hospitalization indicate that the probabilities that PP with pegfilgrastim, PP with lipegfilgrastim, and PP with filgrastim (11-day) are cost effective are $52.7,19.8$, and $15.2 \%$, respectively, for breast cancer and 59.8, 19.6, and $11.9 \%$, respectively, for NHL.

\section{Discussion}

We found that PP with pegfilgrastim relative to SP with pegfilgrastim was associated with ICERs of $€ 15,500 /$ QALY for stage II breast cancer treated with TC and $€ 7800 / \mathrm{Q} A \mathrm{Y}$ for NHL treated with R-CHOP; other comparators were either dominated by PP or SP with pegfilgrastim or eliminated via extended dominance. Of note, for both cancer/chemotherapy scenarios, while SP with pegfilgrastim was on the cost-effectiveness frontier (i.e., not dominated or eliminated via extended dominance) in the base-case analysis, in the PSA, the probability that SP with pegfilgrastim was cost effective at a willingness-to-pay threshold of $€ 30,000 / \mathrm{QALY}$ was $<1 \%$. Because PP and SP with pegfilgrastim share many parameter values, the ICER between these two strategies was not sensitive to changes in those values.

Of interest to decision makers in Belgium, the PSAs indicate that PP with pegfilgrastim was cost effective relative to SP with pegfilgrastim, lipegfilgrastim, filgrastim, and lenograstim for both cancer/chemotherapy scenarios when using a willingness-to-pay threshold of $€ 30,000$ per QALY [46]. Specifically, based on the PSAs performed for both cancer/chemotherapy scenarios, the probabilities that PP with pegfilgrastim was cost effective at a threshold of $€ 30,000$ per QALY were $52 \%$ for TC-treated stage II breast cancer and 58\% for R-CHOP-treated NHL. All other strategies had probabilities of being cost effective of $<25 \%$ 
a

Proportion of FN Events Requiring Hospitalization (1-0.19) RR of FN, Cycles 2+ (No FN History) (0.29-0.16); BC: 0.21 RR of FN Pegfilgrastim vs. No Prophylaxis (0.19-0.44); BC: 0.29 HR for mortality $\mathrm{RDI}<85 \%$ vs. RDI $\geq 85 \%$ (2.32-1); BC: 1.45

FN Mortality Risk (Per Episode) (0.04-0.03); BC: 0.03 RR of FN, Cycles 2+ (FN History) (13.35-6.19); BC: 9.09 OR for RDI<85\% (FN history) (2.07-1.18); BC: 1.58 Cost of FN (Inpatient) (6359.13-4274.87); BC: 5317 Post-Chemotherapy Utility (Years 5+) (1-0.83); BC: 0.96

b

Cycle 1 Baseline FN Risk (0.29-0.13); BC: 0.21 HR for mortality RDI <90\% vs. RDI $\geq 90 \%$ (3.7-1.19); BC: 2.08 Proportion of FN Events Requiring Hospitalization (1-0.19); BC: 0.84

RR of FN, Cycles 2+ (No FN History) (0.29-0.16); BC: 0.21 Probability of RDI <90\%: FN history, all ages (0.83-0.58); BC: 0.71 RR of FN Pegiligrastim vs. No Prophylaxis (0.19-0.44); BC: 0.29 Cost of FN (Inpatient) (8590.87-5775.13); BC: 7183

RR of FN, Cycles 2+ (FN History) (13.35-6.19); BC: 9.09

Post-Chemotherapy Utility (Years 5+) $(0.96-0.79)$; BC: 0.89 Cost of FN (Post-Hospitalization) (2749.08-1848.04); BC: 2298.56
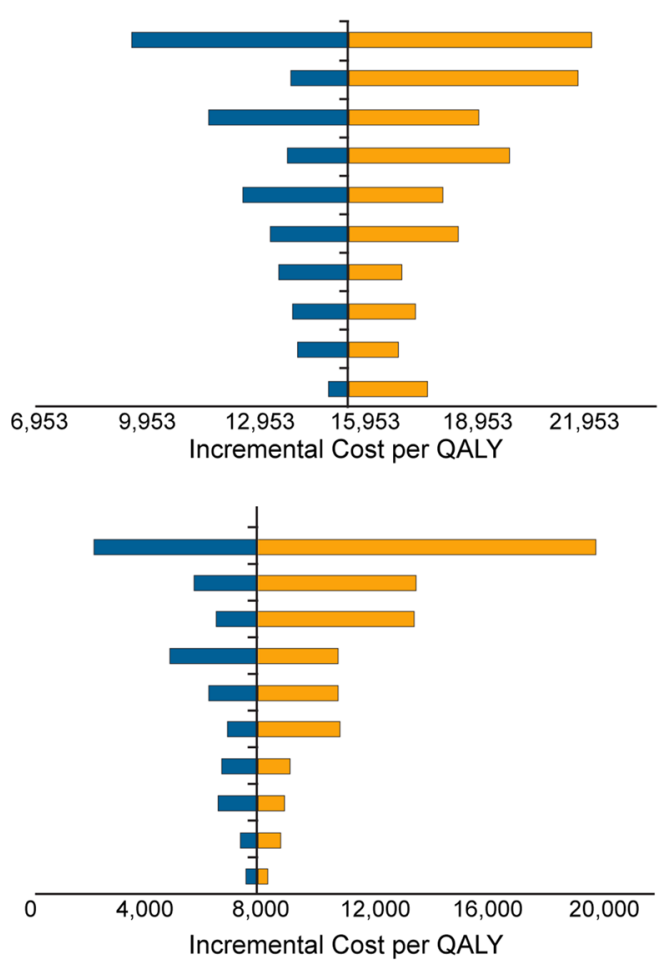

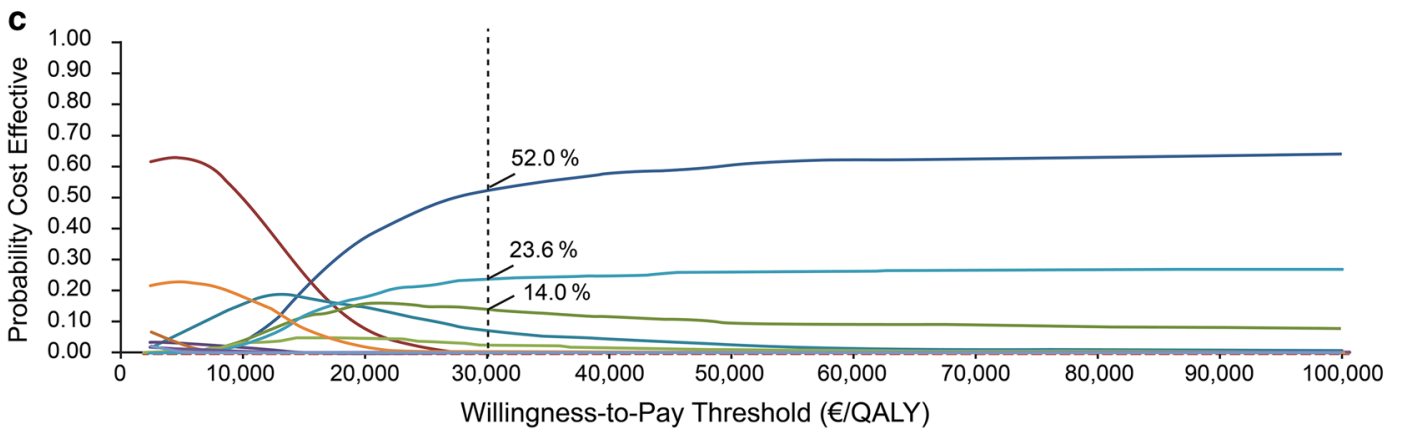

—PP with pegfilgrastim _ _ SP with filgrastim (11-day) — PP with lenograstim (11-day) — SP with lenograstim (6-day) $\begin{array}{llll}\text { - SP with pegfilgrastim } & \text { PP with filgrastim (6-day) — SP with lenograstim (11-day) — PP with lipegfilgrastim } \\ \text { PP with filgrastim (11-day) } & \text { SP with filgrastim (6-day) _ _ PP with lenograstim (6-day) _ SP with lipegfilgrastim }\end{array}$ No prophylaxis

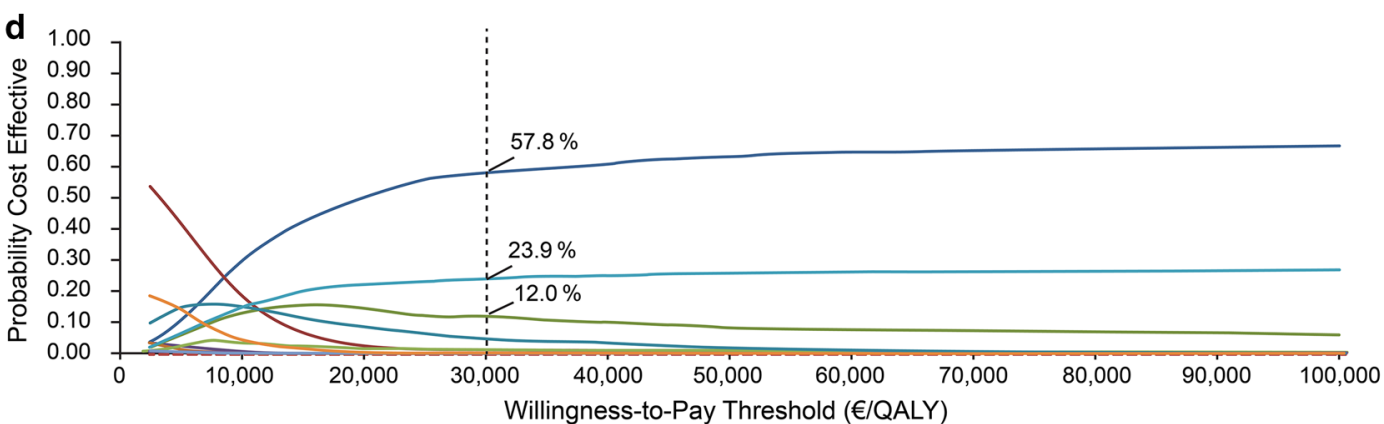

— PP with pegfilgrastim _ _ S SP with filgrastim (11-day) — PP with lenograstim (11-day) — SP with lenograstim (6-day) SP with pegfilgrastim — PP with filgrastim (6-day) - $\quad$ SP with lenograstim (11-day) PP with lipegfilgrastim - PP with filgrastim (11-day) —SP with filgrastim (6-day) — PP with lenograstim (6-day) No prophylaxis 
(ranging from $<1$ to $24 \%$ ). PSA results indicate that there is an approximately $76-82 \%$ chance that PP with a pegylated G-CSF is cost effective. The uncertainty lies in the relative efficacy of pegfilgrastim and lipegfilgrastim, with the evidence suggesting that pegfilgrastim is the cost-effective choice. The wide 95\% CI for the lipegfilgrastim versus pegfilgrastim OR (1.39 [95\% CI 0.54-3.50]) [17] in the PSA contributed to the finding that lipegfilgrastim had a slightly more than $20 \%$ chance of being cost effective at a threshold of $€ 30,000 / \mathrm{QALY}$. Results of DSAs for both regimens indicate that model results were most sensitive to the baseline risk of FN in cycle 1, as well as the proportion of FN events requiring hospitalization and the RR of FN in cycles $\geq 2$ versus cycle 1 (no history of FN) for TC-treated stage II breast cancer, and the mortality HR for an $\mathrm{RDI}<90 \%$ and the proportion of $\mathrm{FN}$ events requiring hospitalization for R-CHOP-treated NHL.

Previous analyses in the European setting examining FN prophylaxis strategies in breast cancer came to similar conclusions. In the UK, a study examining PP and SP of filgrastim, lenograstim, and pegfilgrastim found that pegfilgrastim was the most cost-effective strategy; whether PP or SP was more cost effective depended on the individual patient's FN risk, age, cancer stage, and the price of G-CSF [13]. Similar conclusions regarding the cost effectiveness of PP with pegfilgrastim versus filgrastim have been reported in other studies in the UK, France, and Italy [48-50]. Here, we expanded on past analyses by including lipegfilgrastim and using updated relative efficacy values for all strategies, as based on a mixed-treatment comparison analysis [17]. We also examined the various treatment prophylaxis strategies in NHL. Thus, this model is aligned with current HTAs, using updated relevant comparators and evidence, and therefore is pertinent for reimbursement decision making.

Several caveats should be kept in mind regarding these results. The target populations were limited to patients with stage II breast cancer receiving TC and patients with NHL receiving R-CHOP. In the absence of data for NHL, breast cancer data were employed for several parameters (e.g., RR of FN in cycles $2+$ vs. cycle $1, \mathrm{RR}$ of $\mathrm{FN}$ based on FN history, and proportion of FN events requiring hospitalization). Costs of $\mathrm{FN}$ events not requiring hospitalization and post-hospitalization FN costs were based on percentages obtained from Weycker et al. [39], a study of metastatic breast cancer, and Weycker et al. [42], a study of multiple tumor types (including breast cancer and NHL). The baseline risk of FN in cycle 1 was assumed to be the same for R-CHOP and CHOP. Survival statistics were based on Netherlands Cancer Registry data for the first 10 years and then extrapolated from 11 to 20 years to capture long-term breast cancer and NHL survival. The utility estimates used in the base-case analysis were obtained from clinical staff (including a physician and nurse focus group and a survey of oncology nurses) rather than directly from patients or from applying a utility scale based on community preferences such as the EQ-5D. Unfortunately, no patient or EQ-5D data were available for health states related to FN. Despite this limitation, DSAs indicate that the model results were not sensitive to utility values. Model comparators were limited to G-CSFs and did not include antibiotics (antibacterials), as the European Organisation for Research and Treatment of Cancer (EORTC) guidelines indicate that antibiotic use in the prevention of FN is controversial [1]. Regarding biosimilars, the biosimilar filgrastim [Nivestim ${ }^{\mathrm{TM}}$ (Hospira, a Pfizer Company, Lake Forest, IL, USA)] entered the Belgian market at the time of these analyses and was therefore not included in the model. The two other biosimilars, TevaGrastim ${ }^{\circledR}$ (Teva, Petach Tikva, Israel) and Zarzio ${ }^{\circledR}$ (Sandoz, a Novartis Company, Princeton, NJ, USA), were available in Belgium at identical prices as the originator, and therefore are already covered in the model.

Although patients receiving G-CSFs had a higher incidence of bone pain than patients receiving placebo in clinical trials [5-8], adverse events related to G-CSF use were not included in the model. The treatment for bone pain is analgesics, which are inexpensive relative to the hospitalization cost of FN, and the incidence of bone pain is similar for all G-CSFs. Further, given the lifetime horizon, any disutility associated with bone pain would be incurred for a relatively short period of time. Accordingly, it was expected that including bone pain would have a minimal impact on the cost-effectiveness results. Two studies [51, 52] included musculoskeletal pain in their analyses. However, results of the DSA performed by Lee et al. [52] indicated that bone pain did not have a significant impact on model results (bone pain did not appear in the top 10 parameters of their DSA), and bone pain did not appear to be a significant driver of model results in the publication by Chan et al. [51]. Lastly, for NHL, although in Bosly et al. [23] only an RDI $<90 \%$ was included in the multivariate model, the unadjusted results also suggest shorter overall survival for those with an RDI $<85 \%$. Of note, modeling mortality as a function of an RDI $<90 \%$ may only underestimate the complete effects of reduced $\mathrm{RDI}$.

\section{Conclusion}

We developed a model that simultaneously compares no prophylaxis, PP, and SP with various G-CSF treatment strategies. Assuming a willingness-to-pay threshold in Belgium of $€ 30,000 / Q A L Y$ [46], the results of our analyses indicate that PP with pegfilgrastim should be considered cost effective relative to other prophylaxis strategies for 
stage II breast cancer treated with TC and NHL treated with R-CHOP.

Acknowledgements These data were presented in part at the 2015 International Society for Pharmacoeconomics and Outcomes Research (ISPOR) 20th Annual International Meeting.

Author contributions All authors were involved in study design and data analysis and interpretation; $\mathrm{KF}, \mathrm{MM}, \mathrm{AP}, \mathrm{LS}$, and $\mathrm{CH}$ were involved in data acquisition.

Transparency declaration The lead author, Kelly Fust (the manuscript's guarantor), affirms that this manuscript is an honest, accurate, and transparent account of the study being reported; that no important aspects of the study have been omitted; and that any discrepancies from the study as planned (and, if relevant, registered) have been explained.

\section{Compliance with Ethical Standards}

Funding This study was funded by Amgen Inc. Susanna Mac of Amgen Inc. provided medical writing assistance.

Conflict of interest KF, MM, AP, and LS have been paid consultants for Amgen Inc. XL, GV, RB, and $\mathrm{CH}$ are employees of Amgen Inc. MW has been a consultant to OptumInsight under contract with Amgen Inc. GL is the principal investigator of a research grant to the Fred Hutchinson Cancer Research Center from Amgen Inc.

Ethical approval For this type of study, formal consent is not required. This article does not contain any studies with human participants or animals performed by any of the authors.

Open Access This article is distributed under the terms of the Creative Commons Attribution-NonCommercial 4.0 International License (http://creativecommons.org/licenses/by-nc/4.0/), which permits any noncommercial use, distribution, and reproduction in any medium, provided you give appropriate credit to the original author(s) and the source, provide a link to the Creative Commons license, and indicate if changes were made.

\section{References}

1. Aapro MS, Bohlius J, Cameron DA, Dal Lago L, Donnelly JP, Kearney N, et al. European Organisation for Research and Treatment of Cancer. 2010 update of EORTC guidelines for the use of granulocyte-colony stimulating factor to reduce the incidence of chemotherapy-induced febrile neutropenia in adult patients with lymphoproliferative disorders and solid tumours. Eur J Cancer. 2011;47(1):8-32.

2. Caggiano V, Weiss RV, Rickert TS, Linde-Zwirble WT. Incidence, cost, and mortality of neutropenia hospitalization associated with chemotherapy. Cancer. 2005;103(9):1916-24.

3. Kuderer NM, Dale DC, Crawford J, Cosler LE, Lyman GH. Mortality, morbidity, and cost associated with febrile neutropenia in adult cancer patients. Cancer. 2006;106(10):2258-66.

4. Wildiers H, Reiser M. Relative dose intensity of chemotherapy and its impact on outcomes in patients with early breast cancer or aggressive lymphoma. Crit Rev Oncol Hematol. 2011;77(3):221-40.
5. Neulasta ${ }^{\circledR}$ (pegfilgrastim) summary of product characteristics. Breda: Amgen; 2011.

6. NEUPOGEN ${ }^{\circledR}$ (filgrastim) summary of product characteristics. Breda: Amgen; 2014.

7. Lonquex ${ }^{\circledR}$ (lipegfilgrastim) summary of product characteristics. Haarlem: Teva Pharmaceuticals; 2013.

8. Granocyte ${ }^{\circledR}$ (lenograstim) summary of product characteristics. London: Chugai Pharma; 2014.

9. Green MD, Koelbl H, Baselga J, Galid A, Guillem V, Gascon P, et al. A randomized double-blind multicenter phase III study of fixed-dose single-administration pegfilgrastim versus daily filgrastim in patients receiving myelosuppressive chemotherapy. Ann Oncol. 2003;14(1):29-35.

10. Holmes FA, O'Shaughnessy JA, Vukelja S, Jones SE, Shogan J, Savin M, et al. Blinded, randomized, multicenter study to evaluate single administration pegfilgrastim once per cycle versus daily filgrastim as an adjunct to chemotherapy in patients with high-risk stage II or stage III/IV breast cancer. J Clin Oncol. 2002;20(3):727-31.

11. von Minckwitz G, Kummel S, du Bois A, Eiermann W, Eidtmann $\mathrm{H}$, Gerber B, et al. Pegfilgrastim $+/-$ ciprofloxacin for primary prophylaxis with TAC (docetaxel/doxorubicin/cyclophosphamide) chemotherapy for breast cancer. Results from the GEPARTRIO study. Ann Oncol. 2008;19(2):292-8.

12. Lyman GH, Lalla A, Barron RL, Dubois RW. Cost-effectiveness of pegfilgrastim versus filgrastim primary prophylaxis in women with early-stage breast cancer receiving chemotherapy in the United States. Clin Ther. 2009;31(5):1092-104.

13. Whyte S, Cooper KL, Stevenson MD, Madan J, Akehurst R. Cost-effectiveness of granulocyte colony-stimulating factor prophylaxis for febrile neutropenia in breast cancer in the United Kingdom. Value Health. 2011;14(4):465-74.

14. Fust K, Li X, Maschio M, Barron R, Weinstein MC, Parthan A, et al. Cost-effectiveness of prophylaxis treatment strategies for febrile neutropenia in patients with recurrent ovarian cancer. Gynecol Oncol. 2014;133(3):446-53.

15. Lyman G, Lalla A, Barron R, Dubois RW. Cost-effectiveness of pegfilgrastim versus 6-day filgrastim primary prophylaxis in patients with non-Hodgkin's lymphoma receiving CHOP-21 in United States. Curr Med Res Opin. 2009;25(2):401-11.

16. Hill G, Barron R, Fust K, Skornicki ME, Taylor DC, Weinstein $\mathrm{MC}$, et al. Primary vs secondary prophylaxis with pegfilgrastim for the reduction of febrile neutropenia risk in patients receiving chemotherapy for non-Hodgkin's lymphoma: cost-effectiveness analyses. J Med Econ. 2014;17(1):32-42.

17. Wang L, Baser O, Kutikova L, Page JH, Barron RL. The impact of primary prophylaxis with granulocyte colony-stimulating factors on febrile neutropenia during chemotherapy: a systematic review and meta-analysis of randomized controlled trials. Support Care Cancer. 2015;23(11):3131-40.

18. Younis T, Rayson D, Thompson K. Primary G-CSF prophylaxis for adjuvant TC or FEC-D chemotherapy outside of clinical trial settings: a systematic review and meta-analysis. Support Care Cancer. 2012;20(10):2523-30.

19. Osby E, Hagberg H, Kvaloy S, Teerenhovi L, Anderson H, Cavallin-Stahl E, et al. CHOP is superior to CNOP in elderly patients with aggressive lymphoma while outcome is unaffected by filgrastim treatment: results of a Nordic Lymphoma Group randomized trial. Blood. 2003;101(10):3840-8.

20. Dutch Cancer Figures. Breast cancer by stage, TNM 6e editie (2003-2009). http://www.cijfersoverkanker.nl/p=57c73326adbaf. Accessed 30 Aug 2016.

21. Dutch Cancer Figures. Non-Hodgkin lymphoma, 2004-2007. http://www.cijfersoverkanker.nl/p=57c87f8ee7324. Accessed 1 Sept 2016. 
22. World Health Organization Global Health Observatory Data Repository. Life expectancy: life tables by country (Belgium). http://apps.who.int/gho/data/view.main.LT61950?lang=en. Accessed 13 June 2014.

23. Bosly A, Bron D, Van Hoof A, De Bock R, Berneman Z, Ferrant $A$, et al. Achievement of optimal average relative dose intensity and correlation with survival in diffuse large B-cell lymphoma patients treated with CHOP. Ann Hematol. 2008;87(4):277-83.

24. Chirivella I, Bermejo B, Insa A, Perez-Fidalgo A, Magro A, Rosello S, et al. Optimal delivery of anthracycline-based chemotherapy in the adjuvant setting improves outcome of breast cancer patients. Breast Cancer Res Treat. 2009;114(3):479-84.

25. Shayne M, Crawford J, Dale DC, Culakova E, Lyman GH, ANC Study Group. Predictors of reduced dose intensity in patients with early-stage breast cancer receiving adjuvant chemotherapy. Breast Cancer Res Treat. 2006;100(3):255-62.

26. Pettengell R, Bosly A, Szucs T, Jackisch C, Leonard R, Paridaens $\mathrm{R}$, et al. INC-EU prospective observational European neitropenia study: preliminary Hodgkin and non-Hodgkin lymphoma results. Poster presented in 11th Congress of the European Hematology Association; Amsterdam; 15-18 June 2006.

27. Hillner BE, Smith TJ, Desch CE. Efficacy and cost-effectiveness of autologous bone marrow transplantation in metastatic breast cancer. Estimates using decision analysis while awaiting clinical trial results. JAMA. 1992;267(15):2055-61.

28. Doorduijn JK, van der Holt B, van Imhoff GW, van der Hem KG, Kramer MH, van Oers MH, et al. CHOP compared with CHOP plus granulocyte colony-stimulating factor in elderly patients with aggressive non-Hodgkin's lymphoma. J Clin Oncol. 2003;21(16):3041-50.

29. Uyl-de Groot CA, Hagenbeek A, Verdonck LF, Lowenberg B, Rutten FF. Cost-effectiveness of ABMT in comparison with CHOP chemotherapy in patients with intermediate- and highgrade malignant non-Hodgkin's lymphoma (NHL). Bone Marrow Transplant. 1995;16(3):463-70.

30. Brown RE, Hutton J. Cost-utility model comparing docetaxel and paclitaxel in advanced breast cancer patients. Anticancer Drugs. 1998;9(10):899-907.

31. Brown RE, Hutton J, Burrell A. Cost effectiveness of treatment options in advanced breast cancer in the UK. Pharmacoeconomics. 2001;19(11):1091-102.

32. Lloyd A, Nafees B, Narewska J, Dewilde S, Watkins J. Health state utilities for metastatic breast cancer. $\mathrm{Br} \mathrm{J}$ Cancer. 2006;95(6):683-90.

33. Armstrong K, Chen TM, Albert D, Randall TC, Schwartz JS. Cost-effectiveness of raloxifene and hormone replacement therapy in postmenopausal women: impact of breast cancer risk. Obstet Gynecol. 2001;98(6):996-1003.

34. Liljegren G, Karlsson G, Bergh J, Holmberg L. The cost-effectiveness of routine postoperative radiotherapy after sector resection and axillary dissection for breast cancer stage I. Results from a randomized trial. Ann Oncol. 1997;8(8):757-63.

35. de Haes JC, de Koning HJ, van Oortmarssen GJ, van Agt HM, de Bruyn AE, van Der Maas PJ. The impact of a breast cancer screening programme on quality-adjusted life-years. Int J Cancer. 1991;49(4):538-44.

36. Moeremans K, Caekelbergh K, Spaepen E, Annemans L. Economic aspects and drivers of febrile neutropenia in cancer: a multicentre retrospective analysis in Belgium [abstract]. In: ISPOR 8th Annual European Congress; Florence; 6-8 Nov 2005.

37. Somers L, Malfait M, Danel A. Cost-utility of granulocyte-colony stimulating factors for primary prophylaxis of chemotherapy induced febrile neutropenia in breast cancer patients in Belgium [abstract]. In: ISPOR 15th Annual European Congress; Berlin; 3-7 Nov 2012.

38. Verhoef G, Somers L, Bosly A. Number needed to treat (NNT) and cost-utility of granulocyte-colony stimulating factors (G-
CSF) for primary prophylaxis (PP) of chemotherapy induced febrile neutropenia (FN) In non Hodgkin's lymphoma (NHL) patients in Belgium. Poster presented in Belgian Hematology Society General Annual Meeting; Ghent; 30 Jan-1 Feb 2014.

39. Weycker D, Edelsberg J, Kartashov A, Barron R, Lyman G. Risk and healthcare costs of chemotherapy-induced neutropenic complications in women with metastatic breast cancer. Chemotherapy. 2012;58(1):8-18.

40. Weycker D, Barron R, Kartashov A, Legg J, Lyman GH. Incidence, treatment, and consequences of chemotherapy-induced febrile neutropenia in the inpatient and outpatient settings. J Oncol Pharm Pract. 2014;20(3):190-8.

41. Gerlier L, Lamotte M, Awada A, Bosly A, Bries G, Cocquyt V, et al. The use of chemotherapy regimens carrying a moderate or high risk of febrile neutropenia and the corresponding management of febrile neutropenia: an expert survey in breast cancer and non-Hodgkin's lymphoma. BMC Cancer. 2010;10:642.

42. Weycker D, Malin J, Edelsberg J, Glass A, Gokhale M, Oster G. Cost of neutropenic complications of chemotherapy. Ann Oncol. 2008;19(3):454-60.

43. Belgian Health Care Knowledge Center. Belgian guidelines for economic evaluations and budget impact analyses: second edition. KCE Reports 183C. Health Technology Assessment. 2012. https://kce.fgov.be/publication/report/belgian-guidelines-foreconomic-evaluations-and-budget-impact-analyses-second-edi\#. VuKmTfl97re. Accessed 11 Mar 2016.

44. Gold MR, Siegel JE, Russell LB, Weinstein MC. Cost-effectiveness in health and medicine. New York: Oxford University Press; 1996.

45. Briggs A, Sculpher M, Claxton K. Decision modelling for health economic evaluation. Oxford: Oxford University Press; 2006.

46. Neyt M, Huybrechts M, Hulstaert F, Vrijens F, Ramaekers D. Trastuzumab in early stage breast cancer: a cost-effectiveness analysis for Belgium. Health Policy. 2008;87(2):146-59.

47. Do T, Medhekar R, Bhat R, Chen H, Niravath P, Trivedi MV. The risk of febrile neutropenia and need for G-CSF primary prophylaxis with the docetaxel and cyclophosphamide regimen in early-stage breast cancer patients: a meta-analysis. Breast Cancer Res Treat. 2015;153(3):591-7.

48. Liu Z, Doan QV, Malin J, Leonard R. The economic value of primary prophylaxis using pegfilgrastim compared with filgrastim in patients with breast cancer in the UK. Appl Health Econ Health Policy. 2009;7(3):193-205.

49. Borget I, Di Palma M, Leonard R. Pegfilgrastim-a health economic model to assess overall cost-effectiveness. EJHP Practice. 2009;15(5):58-61.

50. Danova M, Chiroli S, Rosti G, Doan QV. Cost-effectiveness of pegfilgrastim versus six days of filgrastim for preventing febrile neutropenia in breast cancer patients. Tumori. 2009;95:219-26.

51. Chan KK, Siu E, Krahn MD, Imrie K, Alibhai SM. Cost-utility analysis of primary prophylaxis versus secondary prophylaxis with granulocyte colony-stimulating factor in elderly patients with diffuse aggressive lymphoma receiving curative-intent chemotherapy. J Clin Oncol. 2012;30(10):1064-71.

52. Lee EK, Wong WW, Trudeau ME, Chan KK. Cost-effectiveness of prophylactic granulocyte colony-stimulating factor for febrile neutropenia in breast cancer patients receiving FEC-D. Breast Cancer Res Treat. 2015;150(1):169-80.

53. Cooper KL, Madan J, Whyte S, Stevenson MD, Akehurst RL. Granulocyte colony-stimulating factors for febrile neutropenia prophylaxis following chemotherapy: systematic review and meta-analysis. BMC Cancer. 2011;11:404.

54. Dulisse B, Li X, Gayle JA, Barron RL, Ernst FR, Rothman KJ, et al. A retrospective study of the clinical and economic burden during hospitalizations among cancer patients with febrile neutropenia. J Med Econ. 2013;16(6):720-35. 